Notfall Rettungsmed $2017 \cdot 20: 360-362$

DOI 10.1007/s10049-017-0310-x

Online publiziert: 4. Mai 2017

(c) Springer Medizin Verlag GmbH 2017

CrossMark
H. Trentzsch · P. Graeff · S. Prückner

Institut für Notfallmedizin und Medizinmanagement (INM), Klinikum der Universität München, Ludwig-

Maximilians-Universität, München, Deutschland

\section{Erratum zu: E - Wärmeerhalt und Wiedererwärmung}

\section{Für kalte und warme Tage}

\section{Erratum zu:}

Notfall + Rettungsmedizin 2017

20(2):141-153

DOI: $10.1007 / \mathrm{s} 10049-017-0272-\mathrm{z}$

Die Autoren weisen auf Fehler in der - Abb. 1 des bereits veröffentlichten Beitrags hin und bitten, die hier korrigierte Abbildung zu beachten.

Die Autoren bitten darum, die Fehler $\mathrm{zu}$ entschuldigen.

\section{Korrespondenzadresse}

\section{Dr. med. H. Trentzsch}

Institut für Notfallmedizin und Medizinmanagement (INM), Klinikum der Universität München, Ludwig-Maximilians-Universität Schillerstraße 53, 80336 München, Deutschland heiko.trentzsch@med.uni-muenchen.de

\section{Literatur}

1. Brown DJ, Brugger H, Boyd J et al (2012) Accidental hypothermia. NEngl J Med 367:1930-1938

2. Paal P, Gordon L, Strapazzon G et al (2016) Accidental hypothermia-an update: the content of this review is endorsed by the international commission for Mountain Emergency Medicine (ICAR MEDCOM). Scand J Trauma Resusc Emerg Med 24:111 


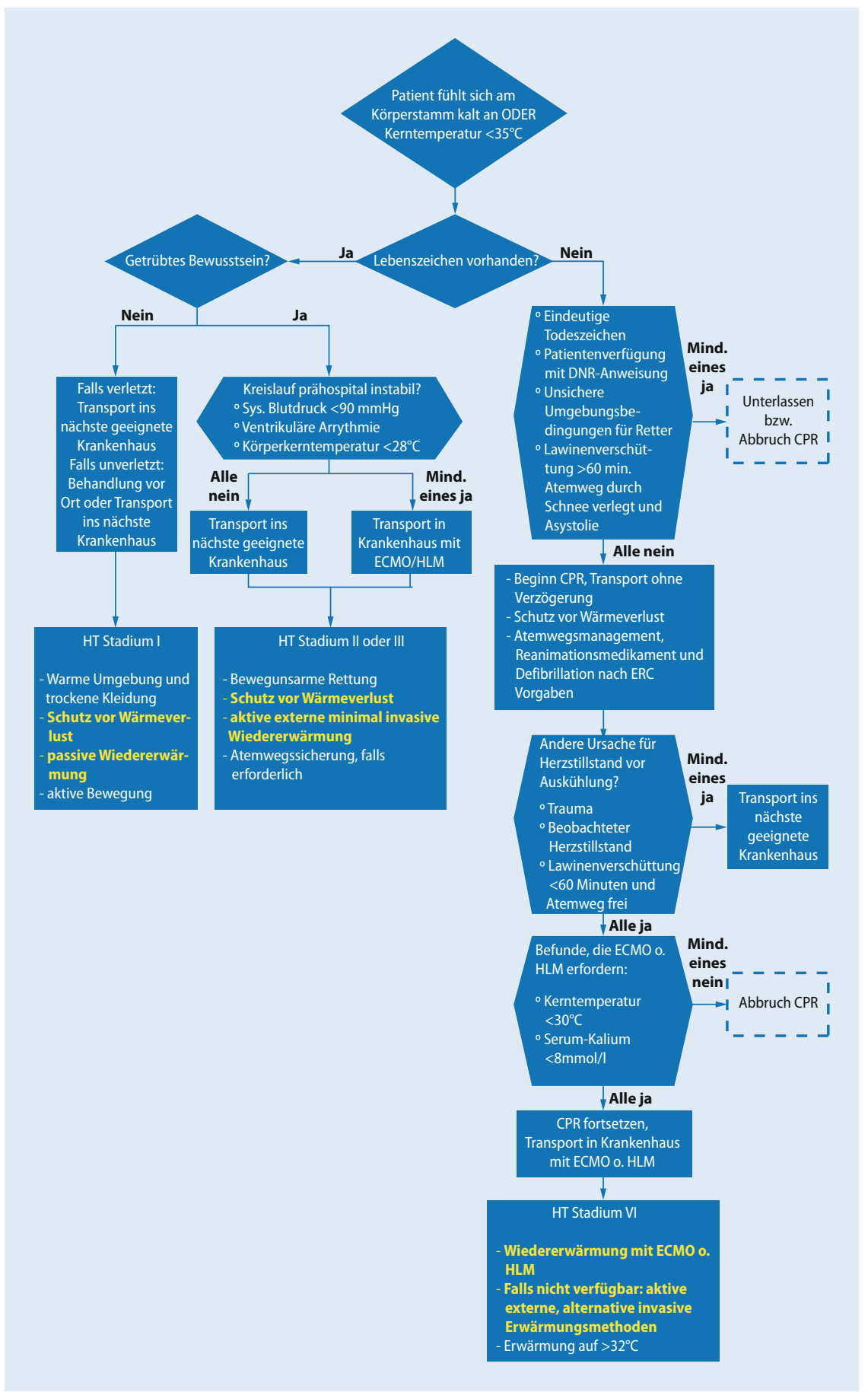

Abb. 1 \& Flowchart für eskalierendes Vorgehen bei der Auswahl verschiedener Produkte für Wärmeerhalt und Wiedererwärmung entsprechend Schweregrad. ECMO Extracorporeal Life Support, HLM Herz-Lungen-Maschine, CPR kardiopulmonale Reanimation. (Nach [1, 2]) 
Hier steht eine Anzeige.

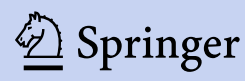

